\title{
Host defence to pulmonary mycosis
}

\author{
Christopher H Mody MD FRCPC FCCP FACP ${ }^{1,2}$, Peter W Warren BSc ${ }^{2}$
}

\begin{abstract}
CH Mody, PW Warren. Host defense to pulmonary mycosis. Can J Infect Dis 1999;10(2):147-155.
OBJECTIVE: To provide a basic understanding of the mechanisms of host defense to pathogenic fungi. This will help physicians understand why some patients are predisposed to fungal infections and update basic scientists on how microbial immunology applies to fungal disease.

DATA SOURCES: English articles from 1966 to present were identified from a MEDLINE search.

STUDY SELECTION: Articles were identified by a MEDLINE search of 'exp lung/' or 'exp lung diseases/' and 'exp fungi/'. The titles and abstracts were screened to identify articles that contained salient information pertaining to host defense of respiratory mycoses.

DATA EXTRACTION: Information was summarized from the articles pertaining to host defense of pulmonary mycosis that had been identified by the MEDLINE search.

DATA SYNTHESIS: Fungi represent a unique and highly diverse group of pathogenic organisms that have become an increasingly prevalent cause of life-threatening illness. A worldwide increase in persons with immunodeficiency has been a major contributing factor to the increase in fungal disease. As a result, clinicians are faced with an expanding array of fungal infections that pose diagnostic and therapeutic challenges. The respiratory tract is the route of acquisition for many important fungal infections; thus, understanding the host defense in the lung is an essential component of understanding host defense to fungal disease. With this understanding, fungi may be divided on the basis of the predilection of certain mycosis for specific immune defects.

CONCLUSIONS: By separating fungi based on the host immune defects that predispose to disease, in conjunction with traditional divisions based on the geographic distribution of fungi, clinicians are able to focus their diagnostic efforts and to identify fungal pathogens better. In addition, an understanding of the normal host defense mechanisms that serve to control fungal infections is essential to the development of novel antifungal therapies.
\end{abstract}

Key Words: AIDS, Fungi, Opportunistic infections, Pulmonary host defense

\section{Mécanisme de défense de l'hôte contre la mycose pulmonaire}

OBJECTIF : Offrir des connaissances de base sur les mécanismes de défense de l'hôte à l'endroit des mycoses afin d'aider les médecins à comprendre pourquoi certains patients sont sujets aux infections fongiques et de renseigner les spécialistes en recherche fondamentale sur l'application de l'immunologie microbienne aux mycoses.

SOURCE DES DONNÉES : Articles de langue anglaise, de 1966 à nos jours, identifiés à l'aide d'une interrogation du réseau MEDLINE.

SÉLECTION DES ÉTUDES : Les articles ont été identifiés lors d'une interrogation du réseau MEDLINE à partir des termes «exp lung/» ou «exp lung diseases/» et "exp fungi/». Les titres et les résumés d'articles ont été passés en revue afin d'identifier les articles qui renferment des renseignements intéressants relatifs au mécanisme de défense de l'hôte face aux mycoses respiratoires. EXTRACTION DES DONNÉES : Les renseignements ont été résumés à partir des articles ayant trait aux mécanismes de défense de l'hôte face aux mycoses pulmonaires qui avaient d'abord été identifiés lors d'une interrogation du réseau MEDLINE. SYNTHÈSE DES DONNÉES : Les champignons forment un groupe très diversifié et unique d'organismes pathogènes qui sont devenus une cause de plus en plus prévalente de maladie à potentiel fatal. L'augmentation du nombre de cas d'immunodéficience à l'échelle mondiale a été un important facteur contributif pour la propagation de la maladie fongique. Par conséquent, les

voir page suivante

\footnotetext{
${ }^{1}$ Departments of Internal Medicine, and ${ }^{2}$ Microbiology and Infectious Disease, The University of Calgary, Calgary, Alberta

Correspondence and reprints: Dr CH Mody, Room 273 HMRB, University of Calgary, Calgary, Alberta T2N 4N1. Telephone 403-220-8479, fax 403-270-8928,e-mail cmody@ucalgary.ca
} 
médecins font face à un éventail de plus en plus varié d'infections fongiques qui posent autant de la défis diagnostiques et thérapeutiques. Les voies respiratoires sont la porte d'entrée de nombreuses infections fongiques majeures. Il est donc important de comprendre les mécanismes de défense pulmonaires de l'hôte si l'on veut saisir de quelle façon son organisme réagit aux mycoses. À la lumière de ces renseignements, on peut regrouper les champignons selon la prédilection de certaines mycoses à l'endroit de certains défauts immunitaires spécifiques.

CONCLUSION : En distinguant les types de champignons en fonction des faiblesses immunitaires de l'hôte qui prédisposent à la maladie en plus d'utiliser les classifications standard fondées sur leur distribution géographique, les médecins peuvent concentrer leurs efforts diagnostiques et identifier plus facilement les organismes pathogènes. De plus, pour lutter contre les infections fongiques et arriver à mettre au point de nouveaux antifongiques, il est important de bien comprendre les mécanismes de défense normaux de l'hôte qui entrent en jeu.

$\mathrm{H}^{\mathrm{s}}$ istorically, fungi represent a group of organisms that have been disregarded by clinicians due to the relative paucity of serious fungal infections. However. the incidence of serious fungal infections has increased 10-fold since 1980 (1). This has prompted the National Institutes of Health, Bethesda, Maryland to classify fungal infection as an "emerging disease", and to devote resources toward the treatment and prevention of fungal diseases. This increase in incidence has been primarily due to an increase in opportunistic fungal infections and attributed to the increased number of patients who are immunosuppressed. Causes of immunosuppression include chemotherapy, other immunosuppressive drugs, AIDS, and both acquired and congenital immunodeficiency disorders. Unfortunately, conventional antifungal chemotherapy is of limited efficacy, and many agents have significant toxicity. Prompt diagnosis and therapy is essential if patients are to have the best chance of survival, and new treatments are required, including immunotherapeutic approaches that might augment conventional antifungal therapy.

The lung serves as the portal of entry for many serious fungal infections. This is because of its close interaction with the environment as well as the ability of many fungal pathogens to become dehydrated and airborne. In the past, the majority of serious fungal infections were seen in immunocompetent hosts, and were caused by fungi with distinct geographic boundaries of distribution. This fact allowed for the classical division of fungal disease based on geographic distribution of the fungal species. However, with the expanding population of immunosuppressed individuals, opportunistic fungi, which are common over large geographic areas, are becoming increasingly important pathogens. Consequently, clinicians must use different diagnostic approaches to identify fungal pathogens correctly. Environmental exposure remains an important determinant of disease, but it is clear that host defence anomalies represent another important determinant that must be addressed in the diagnosis and management of fungal disease.

The most simple and useful clinical division is made on the basis of virulence characteristics. First, fungi can be divided into those that are highly virulent, which cause disease in immunocompetent hosts, versus those that are opportunistic, which only cause disease in immunosuppressed hosts. Opportunistic fungi can be further divided into those that are associated with defective neutrophil function versus those that are associated with $\mathrm{T}$ lymphocyte defects. This division does not predict the severity of the disease caused by the pathogen but the ability of the pathogen to cause disease. Indeed, highly virulent fungi (Blastomyces species, Coccidioides species) can cause mild disease in immunocompetent hosts, while opportunistic fungi (Cryptococcus species) can cause severe and even fatal disease in immunosuppressed hosts.

Dividing fungi into two categories, highly virulent or minimally virulent or opportunistic fungi, is a helpful clinical distinction. The major determinant of disease produced by highly virulent fungi is the exposure to the pathogen. These fungi include the endemic or geographically based fungi such as Histoplasma species, Coccidiodies species or Blastomyces species. Edwards et al (2) obtained an excellent example of the focal geographic distribution of fungi from delayed type hypersensitivity testing to histoplasma antigen in almost 3000 naval recruits between 1956 and 1965; this showed a striking association between a positive reaction and residence near the Ohio and Mississippi River valleys. It is presumed that these fungi possess sufficient virulence to allow them to subvert immunocompetent host defence mechanisms. Of course, not all individuals who are exposed to the virulent or endemic fungi will develop disease. The reasons for this presumably include variations in inocula and subtle variations in host defence. For the highly virulent pathogenic fungi, it is interesting to note that there are genetic factors that control host defence. Studies using inbred strains of mice have demonstrated a wide variation in susceptibility to Histoplasma (3), Blastomyces (4) and Cryptococcus (5) species. Genetic variations in susceptibility have also been demonstrated by epidemiological studies of coccidiodes infections, in which an increase in incidence of 176-fold in Filipinos, 14-fold in African Americans and threefold in Mexican Americans versus the general population were noted $(6,7)$. By contrast, the major determinant of disease for the minimally virulent or opportunistic fungi is the suppression of host defence. Thus, patients with normal immune systems are unlikely to develop infections from these fungi, while patients who have suppressed immune systems are at a much greater risk. The association of opportunistic fungal diseases with specific immune defects gives insight into the essential immune mechanisms responsible for effective clearance in the immunocompetent host. The fungi that should be included in the opportunistic classification include the molds (Aspergillus species, the zygomycetes, Penicillium species) and the yeasts (Candida species, Cryptococcus species, Torulopsis species) in addition to many more.

To understand how fungi cause disease, it is important to understand the mechanisms of host defence in the immunocompetent host. From an understanding of protective host defence mechanisms, it is possible to examine the complex 
TABLE 1

Barrier function of host defense to fungal infections

Aerodynamic filtration

Bronchoconstriction

Cough

Lining fluids

Epithelium

Mucociliary transport

Normal flora

interplay of host and fungal (virulence) factors which dictate whether exposure produces an infection. Host defences to fungi can be divided into barrier functions, resident mechanisms and recruited mechanisms. Each of these aspects of host defence in the lung will be discussed as they pertain to the mycosis.

\section{BARRIER MECHANISMS OF HOST DEFENCE}

To initiate an infection in an immunocompetent host, fungi must actively subvert or take advantage of altered pulmonary barrier mechanisms (Table 1). Barrier mechanisms are important mechanical obstacles that serve to prevent initial colonization and invasion of the lung by pathogenic fungi. Different regions of the lung use different barrier mechanisms to prevent initial colonization and invasion. For instance, mucociliary transport is an important barrier mechanism in the upper airways, but is absent in the lower airways and distal air spaces, while the epithelium is the major barrier mechanism in the terminal airways and air spaces. Although some of these mechanisms of host defence have been demonstrated for the mycoses, others are presumed.

Aerodynamic filtration and bronchoconstriction: Aerodynamic filtration is presumed to be an important aspect of host defence to fungi. Because of the flow characteristics and the branching structure of the lung, particles greater than $5 \mu \mathrm{m}$ in diameter are deposited predominantly in the nasal and pharyngeal areas. In contrast, smaller particles, between 1 and 5 $\mu \mathrm{m}$, are deposited in the central airways, and smaller particles, less than $1 \mu \mathrm{m}$ are deposited primarily in the distal air spaces and alveolar structures, or are not deposited at all (8). Thus, the mass median diameter of most fungi predict that they would be deposited in the proximal and central airways. In addition, proximal deposition is thought to be enhanced by bronchoconstriction, which increases the air velocity and promotes deposition of smaller particles in more proximal sites. Proximal deposition is preferable to distal deposition because of the presence of clearance mechanisms, such as mucociliary transport and cough, that are absent or ineffective in the distal airways and alveoli.

Lining fluids: The lining fluids of the airways are important in bacteriostasis through the actions of lysozyme, nonimmune and immune opsonins, and proteins such as transferrin that sequester vital nutrients. These mechanisms are likely to be important in fungal host defence. An example of this mechanism of
TABLE 2

Resident mechanisms of host defense to fungal infections

Immunoglobulin

Complement

Alveolar macrophages

Surfactant

host defence is the iron-binding proteins, which result in deprivation of essential nutrients for fungi such as histoplasma (9). Epithelium mucociliary transport and cough: The epithelium is an important mechanical barrier. Invasive fungi such as aspergillus have a strong propensity to penetrate the epithelium, and specific mechanisms for recognizing the determinants of epithelial basement membrane have been identified for aspergillus (10) and histoplasma (11). The importance of mucociliary transport is demonstrated by the predisposition of patients with underlying structural lung disease to develop fungal infections. Prior lung disease is a risk factor for aspergillus (12) and sporothrix (13) infections. Cough is a nonspecific mechanism for the rapid clearance of lining fluids, debris and particulate matter from the airways. Cough is presumed to be an important barrier mechanism, although no formal studies have been done to address this possibility. Finally, altered microbial flora play a role in sites where there is normal bacterial colonization including the gut and upper respiratory tract by occupying adherence sites for pathogenic organisms. This is an important determinant of disease for fungi such as aspergillus, in which there is an increased incidence of infection following broad spectrum antibiotics $(14,15)$.

\section{RESIDENT MECHANISMS OF HOST DEFENCE}

The resident mechanisms of host defence are also important for defence to the pathogenic fungi (Table 2). These include the mechanisms that prevail within the air spaces and parenchyma of the lung. Although immunoglobulin and complement have unique characteristics and distribution within the lung, little work has been done on the pulmonary distribution of these molecules as it applies to fungal host defence. Thus, these components will be discussed under recruited mechanisms of host defence.

Alveolar macrophages: Alveolar macrophages are the first 'professional' phagocytic cells that most respirable fungi encounter and provide a vital link between resident and recruited mechanisms through the elaboration of inflammatory mediators. Unfortunately, for most fungi, nonimmune alveolar macrophages have modest fungistatic or fungicidal effect, the exception being the ability to block the conversion of blastomyces conidia to the yeast phase (16). However, nonimmune alveolar macrophages can be activated for potent antifungal activity with cytokines such as gamma-interferon. This has been demonstrated for cryptococcus (17), coccidiodes (18), histoplasma (19) and aspergillus (20), indicating a potential for antifungal activity given the proper milieu.

Surfactant: Surfactant is an important component of host defence to fungi. Although its ability to suppress the growth of 
TABLE 3

Recruited mechanisms of host defense to fungal infections

\author{
Serum factors \\ Complement \\ Immunoglobulins \\ Neutrophils \\ Monocytes/macrophages \\ T lymphocytes and cell mediated immunity \\ Cytokines regulate recruited mechanisms
}

fungi has not been demonstrated as it has for other microbes, surfactant does enhance opsonization of aspergillus conidia (21), and surfactant protein-D (SP-D) causes the agglutination of acapsular Cryptococcus neoformans (22).

\section{RECRUITED MECHANISMS OF HOST DEFENCE}

Recruited mechanisms of host defence have received the greatest attention and have a number of important components (Table 3). Recruited mechanisms are those that are absent from the airways and air spaces in the absence of inflammation. Recruited mechanisms include serum components, such as iron-binding proteins, immunoglobulins and complement that leak into the air spaces following release of inflammatory mediators, and the cells such as Tymphocytes, monocytes, neutrophils and eosinophils that are conscripted into the lung and provide antifungal effects. Additionally, penetration of the fungi into tissues and vascular space also provide exposure to these factors. Recruited mechanisms are of particular importance in the distal airways and air spaces where barrier mechanisms such as mucociliary transport are absent. Serum and complement: Serum has been shown to be directly inhibitory for cryptococcus (23). All pathogenic fungi activate complement, and complement is important in host defence to some fungi. Depletion of complement has been demonstrated to impair host defence to cryptococcus (24) and coccidiodes (25). Both classical and alternate pathways are activated by cryptococcus (26), coccidiodes (27) and blastomyces (28). The polysaccharide of the cell wall of both coccidiodes and cryptococcus bind and activate complement via the alternative pathway. Polysaccharide from coccidiodes binds $\mathrm{C} 1, \mathrm{C} 3, \mathrm{C} 4$ and properidin (25), while cryptococcal polysaccharide binds $\mathrm{C} 3$ and is a potent activator of the alternate complement pathway. Immunoglobulins: Fungi represent a peculiar problem to traditional vaccine development because immunoglobulins contribute minimally to the host defence for many pathogenic fungi. In general, patients who have congenital deficiencies of immunoglobulin production are not predisposed to pathogenic fungi. There has been no significant importance attributed to immunoglobulins in the host defence to histoplasma, aspergillus (29) or blastomyces (30). In contrast, immunoglobulins have been shown to be of modest importance in some mycoses. Immunoglobulins are opsonic for cryptococcus $(31,32)$ and coccidiodes (18), and are protective in murine cryptococcosis (33). However, subtle differences in the epitope specificity and antibody isotype can make tremendous differences in the outcome of the infection (34), as demonstrated by Yuan et al (35), in which IgG1 was protective and IgG3 promoted disease. This may present significant problems for the development of vaccines because the antibody response may need to be isotype specific.

Neutrophils: Neutrophils are an essential component of host defence to some pathogenic fungi such as aspergillus and candida, while they are of less importance to others such as histoplasma, cryptococcus or coccidiodes. It is clear that granulocytopenia and chronic granulomatous disease are major risk factors for invasive aspergillosis $(14,15)$, and it has been demonstrated that aspergillus mycelia are killed by neutrophils $(36,37)$. Candida is readily phagocytosed and killed by neutrophils (38), and neutrophils are essential for host defence to candida in vivo (39). The susceptibility of blastomyces to neutrophils depend on the phase of the fungus. The mycelial phase is very susceptible to neutrophil killing (40), while the yeast phase is less susceptible (41). Neutrophils also have some activity to cryptococcus $(42,43)$; however, cryptococcal mannitol and melanin scavenges reactive oxygen intermediates (44-46), which reduces their effectiveness. The role of neutrophils in histoplasmosis is controversial (47), and coccidiodes spherules are resistant to phagocytosis by neutrophils (48). Coccidiodes arthroconidia and endospores induce neutrophil influx but minimal killing $(48,49)$, although activated neutrophils have some activity to the endospores (50).

Macrophages: Macrophages and monocytes have considerable antifungal activity. The uptake of fungi is via the CR3 receptor, Fc receptor and the mannose receptor. The polysaccharide capsule of cryptococcus (51) and the hyphal outer cell wall of coccidiodes (49) are potent inhibitors of phagocytosis and act as effective virulence factors. Some fungi have the ability to inhibit lysosomal acidification, such as histoplasma (52). Coccidiodes can inhibit phagolysosomal fusion, but activation of macrophages markedly reduces this inhibition (53). It is clear that monocytes and macrophages are important in aspergillus conidia killing (37) and anticryptococcal activity (54). Macrophages are activated by a number of cytokines for antifungal activity, including gamma-interferon, which activates macrophages for antihistoplasma (55), anticryptococcus (56) and anticoccidiodes (57) activity. Granulocyte-macrophage colony- stimulating factor (GM-CSF) (58) and macrophageCSF (M-CSF) (59) also have considerable ability to activate macrophages for antifungal activity.

T lymphocytes and cell-mediated immunity: Cell-mediated immunity is essential for host defence to some fungi, including cryptococcus, histoplasma and coccidiodes. Fungi have been shown to inhibit cellular immune responses. For instance, macrophages can be induced to suppress cell-mediated immunity via production of prostaglandin E2 in coccidiodomycosis (60). Additionally, a complex cascade of T suppressor cells is induced by $C$ neoformans (61). Interestingly, while neutrophils are essential for protection against disseminated candidiasis, cell-mediated immunity appears to be the major mechanism of protection against mucocutaneous candidiasis. There is a strong clinical association between AIDS and invasive histoplasmosis (62), cryptococcosis (63) and coccidiodomycosis $(64,65)$, suggesting that cell-mediated immunity is critical. 
The importance of cell-mediated immunity has been demonstrated further by studies where the transfer of immune lymphocytes to naive syngeneic recipients has afforded protection against histoplasmosis (66), blastomycosis (67) and coccidiodomycosis (68). It has been demonstrated that both CD4 and CD8 cells participate in host defence to cryptococcus $(56,69)$ and histoplasma (70). However, cell-mediated immunity is of minimal importance for some mycoses. In a murine model of aspergillosis, T cell deficient mice are no more susceptible than T cell sufficient mice (71). In addition, AIDS patients are only susceptible to aspergillus at the very terminal stages of their disease (72). This is likely due to a combination of the limited number of CD4 cells available to activate neutrophils appropriately to kill aspergillus in combination with the neutropenia associated with end-stage AIDS.

Mechanisms of killing: A number of mechanisms of fungal killing have been identified, and include oxidative and nonoxidative mechanisms. Oxygen-mediated killing has been demonstrated for a large number of fungi including histoplasma (73) and cryptococcus (74). The importance of oxidative killing mechanisms in the clearance of cryptococcus is evident in the ability of cell wall melanin to act as a potent virulence factor in a murine model of cryptococcosis by scavenging reactive oxygen intermediates $(45,46)$. Considerable attention and importance have been demonstrated for nitric oxide-mediated killing of fungi in animal models, although its importance in the human host defence is controversial. This was first identified for cryptococcus (75) and subsequently demonstrated for histoplasma (76), among others. By contrast, nitric oxide-mediated mechanisms are not important in macrophage-mediated killing of aspergillus (78) or histoplasma (73).

Fungi are also susceptible to nonoxidative killing mechanisms used by natural killer cells, T lymphocytes and neutrophils. The importance of natural killer cells in microbial host defence is usually confined to their ability to lyse virally infected cells and to release cytokines such as gamma-interferon. Natural killer cells were initially shown to have direct anticryptococcal activity in early studies by Murphy and McDaniel (79). This has further been demonstrated for coccidiodes (80). Natural killer cells also release gamma-interferon in response to $C$ neoformans (81), which can activate oxidative killing mechanisms in macrophages. Similarly, T lymphocytes also have direct antifungal activity as demonstrated for cryptococcus $(82,83)$. This $\mathrm{T}$ lymphocyte-mediated antifungal activity occurs via an unknown mechanism, but is not due to oxidation, nitric oxide, protease or prostaglandin release (84). Finally, neutrophils have potent in vitro antihistoplasma activity that has been localized to the azurophil granules of neutrophils, and antihistoplasma activity is not deficient in neutrophils from donors with chronic granulomatous disease (85).

Cytokines in fungal infections: A considerable amount of work has been done on the cytokine responses to pathogenic fungi. Cytokines are important in resident host defence mechanisms through activation of alveolar macrophages and are essential in the promotion of recruited host defence mechanisms. The role of cytokines has been demonstrated in many aspects of fungal pathogenesis. Cytokines have clearly been demon- strated to enhance host defence in some fungal diseases. For example, interleukin (IL)-12 administration to mice is protective in histoplasmosis (86); tumour necrosis factor-alpha (TNF- $\alpha$ ), gamma-interferon and IL-12 all prolong the survival in a murine model of cryptococcosis $(87,88)$.

It is clear that different cytokines exert their effects at different stages of the immune response to fungi, and that individual cytokines have pleotropic activities. Perhaps the best example is TNF-a, which has different but critical contributions during the afferent phase and efferent phase of the immune response against $C$ neoformans (89). Indeed, many components of the immune response to fungi are enhanced by modulating cytokine production. For example, M-CSF enhances the phagocytosis of aspergillus by macrophages (20), and tumor necrosis factor alpha and GM-CSF enhance ingestion of $C$ neoformans (90). A great deal of work has also been done on the ability of cytokines to enhance killing. Granulocyte-CSF enhances neutrophil-mediated killing of aspergillus (91), rhizopus (91), candida and cryptococcus (43). M-CSF has been demonstrated to enhance macrophagemediated killing of aspergillus (20), histoplasma (73) and cryptococcus (59). Gamma-interferon is also a potent activator for antifungal activity. Its broad range of activity includes its ability to activate neutrophils for aspergillus killing (20), and it is critical for nitric-oxide induced killing of cryptococcus (93).

There is some evidence that the TH1/TH2 paradigm holds for fungal infections. Current dogma dictates that a TH1 response (gamma-interferon, IL-12) would confer protection, and a TH2 (IL-10, IL-4) response would confer susceptibility to organisms such as Coccidiodes and Cryptococcus that are cleared by cell-mediated immune mechanisms. Indeed, in coccidioidomycosis, resistant $\mathrm{DBA} / 2$ mice produce gammainterferon, while susceptible BALB/c mice produce IL-4 (94), and IL-12 converts susceptible mice to the resistant phenotype through the induction of gamma-interferon (95). Additionally, in cryptococcosis, a TH1 immune response in C.B-17 mice conferred resistance, whereas the absence of this response in C57BL/6 mice conferred susceptibility (51).

Considering the importance of cytokines in host defence to fungal infections, it is not surprising that inhibition of cytokine production by fungi is an effective virulence mechanism. AfD from aspergillus inhibits the synthesis of TNF- $\alpha$ and IL- 6 via inhibition of nuclear factor kappa B and AP-I transcriptional factors (96). Additionally, the capsule of $C$ neoformans has been demonstrated to be immunosuppressive via induction of IL-10 (97), which in turn inhibits the production of protective cytokines such as TNF- $\alpha$.

There is some evidence that patients who have developed disseminated mycoses have impaired cytokine production. It has been demonstrated that cytokine release from peripheral blood mononuelear cells in response to $C$ neoformans is delayed in patients with human immunodeficiency virus (HIV) (98), and gamma-interferon and IL-12 are reduced in patients with disseminated coccidiodomycosis (99). The implication of this work is that the patients developed disseminated disease because of an underlying defect in cytokine production. How- 
TABLE 4

Important mechanisms of host defence to pathogenic fungi

\begin{tabular}{lcccc}
\hline & Neutrophil & $\begin{array}{c}\text { T cell/ } \\
\text { monocyte }\end{array}$ & Antibody & $\begin{array}{c}\text { Barrier } \\
\text { mechanisms }\end{array}$ \\
\hline Candida & +++ & +++ & + & ++ \\
Aspergillus & +++ & $-/+$ & - & + \\
$\begin{array}{l}\text { Zygomycete } \\
\text { species }\end{array}$ & +++ & $?$ & - & + \\
Cryptococcus & + & +++ & + & $?$ \\
Histoplasma & - & +++ & - & $?$ \\
Coccidiodes & $-/+$ & +++ & + & $?$ \\
Blastomyces & ++ & ++ & $?$ & $?$ \\
\hline
\end{tabular}

ever, it has not been established definitively whether this is the cause or effect of the mycosis.

Influence of immunosuppressive drugs: Immunosuppressive drugs are used in a variety of settings including inflammatory diseases, organ transplantation and chemotherapy. Patients receiving immunosuppressive drugs are at an increased risk of fungal infection. In fact, fungal infections are the leading cause of mortality among transplant patients (100). These drugs have variable effects on the immune system depending on their relative selectivity for different cell lines and stages of maturation. For instance, drugs such as cyclosporine, azathioprine and mycophenolate, which are used in the setting of organ transplantation and inflammatory disease, are highly selective for mature, proliferating $\mathrm{T}$ lymphocytes and have little direct effect on neutrophils (101). However, patients receiving organ transplants are most susceptible to aspergillus and candida infections (100), infections that are controlled by neutrophils. This is likely due to the indirect effect of suppression of cytokine 'help' provided by T lymphocytes rather than direct effect on neutrophils. In addition, the disruption of barrier mechanisms through surgery, broad spectrum antibiotic use and other microtrauma provide additional risk factors for fungal infection. Indeed, there are large differences in the rate of fungal infection depending on the organ that is transplanted such that funeral infections are more

\section{REFERENCES}

1. Dixon DM, McNeil MM, Cohen ML, Gellin BG, La Montagne JR. Fungal infections: a growing threat. Public Health Rep 1996;111:226-35.

2. Edwards LB, Acquaviva FA, Livesay VT, et al. An atlas of sensitivity to tuberculin, PPD-B, and histoplasmin in the United States. Am Rev Respir Dis 1969;99:4(Suppl):1-132.

3. Wu-Hsieh B. Relative susceptibilities of inbred mouse strains C57B1/6 and A/J to infection with Histoplasma capsulatum. Infect Immun 1989;57:3788-92.

4. Morozumi PA, Halpern JW, Stevens DA. Susceptibility differences of inbred strains of mice to blastomycosis. Infect Immun 1981;32:160.

5. Hoag KA, Street NE, Huffnagle GB, Lipscomb MF. Early cytokine production in pulmonary Cryptococcus neoformans infections distinguishes susceptible and resistant mice. Am J Respir Cell Mol Biol 1995;13:487-95. common with heart transplant (102) than renal transplant (103). In contrast, many chemotherapeutic drugs such as cytarabine, fludarabine and azacytidine cause profound, combined neutropenia and lymphopenia through bone marrow suppression (101). Patients receiving these drugs are at a similar risk of serious aspergillus and candida infections (104) as those receiving anti-inflammatory or antirejection drugs. However, the risk in this case is likely due to an absolute reduction in the numbers of neutrophils.

\section{CONCLUSION}

Although tremendous knowledge has been gained about the host defence to fungi, it is clear that the mechanisms are complex, and subtle perturbations can trigger detrimental rather than protective responses. It is clear that we have insufficient information about fungal virulence factors and the interaction of various components of the immune system to develop optimal immune therapeutic strategies. Further work is required to develop these treatments. However, some approaches are being attempted. A vaccine has been developed for cryptococcus that conjugates the cryptococcal capsular glucuronoxylomannan with tetanus toxoid. This vaccine has entered clinical evaluation (105). Additionally, there have been proposals for gamma-interferon and IL-12 therapy for various fungal infections $(106,107)$.

Some fungi are highly virulent and endemic in certain areas of North America (histoplasma, blastomyces and coccidiodes), while others are less virulent and ubiquitous (cryptococcus, candida and aspergillus). This distinction allows clinicians to focus their diagnostic and therapeutic approach according to the exposure risk of their patient as determined by the pathogenic fungi endemic to the area and the travel history of the patient. An additional approach is based on the fact that host defence to fungi allows for the separation of pathogenic organisms into two broad categories (Table 4). For some fungi (candida, aspergillus and zygomycetes), neutrophils are the most important effector cell, while for other fungi (cryptococcus, histoplasma and coccidiodes) $\mathrm{T}$ cells and cellmediated immunity are the most important component of host defence. This is a helpful clinical distinction that allows physicians to focus their diagnostic efforts based on the specific immunodeficiency of their patients.

6. Gifford MA, Buss WC, Douds RJ. Data on coccidioides fungus infection, Kern County 1901-1936. Kern County Health Department Annual Report, 1937:39-54.

7. Johnson WM. Racial factors in coccidioidomycosis: mortality experience in Arizona. Ariz Med 1982;39:18-24.

8. Morrow DE. Health Phys 1966;12:173.

9. Lane RE, Wu-Hsieh BA, Howard DH. Iron limitation and the gamma-interferon-mediated antihistoplasma state of murine macrophages. Infect Immun 1991;59:2274-8.

10. Bouchara JP, Sanchez M, Chevailler A, et al. Sialic acid-dependent recognition of laminin and fibrinogen by Aspergillus fumigatus conidia. Infect Immun 1997;65:2717-24.

11. McMahon JP, Wheat J, Sobel ME, Pasula R, Downing JF, Martin WJ 2nd. Murine laminin binds to Histoplasma capsulatum. A possible mechanism of dissemination. J Clin Invest 1995;96:1010-7. 
12. Young RC, Bennett JE, Vogal CL, et al. Aspergillosis: The spectrum of disease in 98 patients. Medicine 1970;49:147-73.

13. Pluss JL, Opal SM. Pulmonary sporotrichosis: Review of treatment and outcome. Medicine 1986;65:143-52.

14. Gerson SL, Talbot GH, Hurwitz S, Strom BL, Lusk EJ, Cassileth PA. Prolonged granulocytopenia: The major risk factor for invasive pulmonary aspergillosis in patients with acute leukemia. Ann Intern Med 1984;100:345-51.

15. Gustafson RL, Schaffner W, Lavely GB, Stratton CW, Johnson HK, Hutcheson RHJ. Invasive aspergillosis in renal transplant recipients: Correlation with corticosteroid therapy. J Infect Dis 1983;148:230-8.

16. Sugar AM, Picard M. Macrophage- and oxidant-mediated inhibition of the ability of live Blastomyces dermatitidis conidia to transform to the pathogenic yeast phase implications for the pathogenesis of dimorphic fungal infections. J Infect Dis 1991;163:371-5.

17. Mody CH, Tyler CL, Sitrin RG, Jackson C, Toews GB. Interferon-gamma activates rat alveolar macrophages for anticryptococcal activity. Am J Respir Cell Mol Biol 1991;5:19-26.

18. Beaman L, Holmberg CA. In vitro response of alveolar macrophages to infection with Coccidoides immitis. Infect Immun 1980;28:234-48.

19. Brummer E, Stevens DA. Antifungal mechanisms of activated murine bronchoalveolar or peritoneal macrophages for Histoplasma capsulatum. Clin Exp Immunol 1995;102:65-70.

20. Roilides E, Sein T, Holmes A, et al. Effects of macrophage colony-stimulating factor on antifungal activity of mononuclear phagocytes against Aspergillus fumigatus. J Infect Dis 1995;172:1028-34.

21. Madan T, Eggleton $\mathrm{P}$, Kishore U, et al. Binding of pulmonary surfactant proteins A and D to Aspergillus fumigatus conidia enhances phagocytosis and killing by human neutrophils and alveolar macrophages. Infect Immun 1997;65:3171-9.

22. Schelenz S, Malhotra R, Sim RB, Holmskov U, Bancroft GJ. Binding of host collectins to the pathogenic yeast Cryptococcus neoformans: human surfactant protein $\mathrm{D}$ acts as an agglutinin for acapsular yeast cells. Infect Immun 1995;63:3360-6.

23. Baum GL, Artis D. Characterization of the growth inhibition factor for Cryptococcus neoformans (GIFc) in human serum. Am J Med Sci 1963;246:87-91.

24. Dromer J, Perronne C, Barge J, Vilde JL, Yeni P. Role of IgG and the complement component $\mathrm{C} 5$ in the initial course of experimental cryptococcosis. Clin Exp Immunol 1989;78:412-7.

25. Halde C, McNall EG, Newcomer VD, Stemberg TH. Properdin levels in mice and man with coccidioidomycosis during soluble amphotericin B administration. Antibiot Annu 1957;598-601.

26. Kozel TR. Activation of the complement system by the capsule of Cryptococcus neoformans. Curr Top Med Mycol 1993;5:1-26.

27. Galgiani JN, Yam PP, Petz LD, Williams P, Stevens DA. Complement activation by Coccidioides immitis: in vitro and clinical studies. Infect Immun 1980,28:944-9.

28. Zhang MX, Klein B. Activation, binding, and processing of complement component 3 (C3) by Blastomyces dermadititis. Infect Immun 1997;65:1849-55.

29. Goodman NL. Aspergillosis. Clin Microbiol Newsl 1982;4:9-11.

30. Brummer E, Morozumi PA, Vo PT, Stevens DA. Protection against pulmonary blastomycosis: Adoptive transfer with T lymphocytes, but not serum, from resistant mice. Cell Immunol 1982;73:349-59.

31. Kozel TR, Highison B, Stratton JC. Localization on encapsulated Cryptococcus neoformans of serum components opsonic for phagocytosis by macrophages and neutrophils. Infect Immun 1984;43:574-9.

32. Aguirre KM, Johnson LL. A role for B cells in resistance to Cryptococcus neoformans in mice. Infect Immun 1997;65:525-30.

33. Mukherjee J, Nussbaum G, Scharff MD, Casadevall A. Protective and nonprotective monoclonal antibodies to Cryptococcus neoformans originating from one B cell. J Exp Med 1995;181:405-9.

34. Nussbaum G, Cleare W, Casadevall A, Scharff NW, Valadon P. Epitope location in the Cryptococcus neoformans capsule is a determinant of antibody efficacy. J Exp Med 1997;185:685-94.

35. Yuan R, Casadevall A, Scharff MD. T cells cooperate with passive antibody to modify Cryptococcus neoformans infection in mice. Proc Natl Acad Sci USA 1997;94:2483-8.

36. Diamond RD, Huber E, Haudenschild CC. Mechanisms of destruction of Aspergillus fumigatus hyphae mediated by human monocytes. J Infect Dis 1983;147:474-83.

37. Schaffner A, Douglas H, Braude A. Selective protection against conidia by mononuclear and against mycelia by polymorphonuclear phagocytes in resistance to Aspergillus. Observations on these two lines of defence in vivo and in vitro with human and mouse phagocytes. J Clin Invest 1982;69:617-31.

38. Lyman CA, Walsh TJ. Phagocytosis of medically important yeasts by polymorphonuclear leukocytes. Infect Immun 1994;62:1489-93.

39. Blasi E, Barluzzi R, Mazzolla R, Bistoni F. Differential host susceptibility to intracerebral infections with Candida albicans and Cryptococcus neoformans. Infect Immun 1993;61:3476-81.

40. Drutz DJ, Frey CL. Intracellular and extracellular defences of human phagocytes against Blastomyces dermatitidis conidia and yeasts. J Lab Clin Med 1985;105:737.

41. Sixbey JW, Fields BT, Sun CN, Clark RA, Nolan CM. Interactions between human granulocytes and Blastomyces dermatitidis. Infect Immun 1979;23:41.

42. Lovchik JA, Lipscomb MF. Role for C5 and neutrophils in the pulmonary intravascular clearance of circulating Cryptococcus neoformans. Am J Respir Cell Mol Biol 1993;9:617-27.

43. Vecchiarelli A, Monari C, Baldelli F, et al. Beneficial effect of recombinant human granulocyte colony-stimulating factor on fungicidal activity of polymorphonuclear leukocytes from patients with AIDS. J Infect Dis 1995;171:1448-54.

44. Chaturvedi V, Wong B, Newman SL. Oxidative killing of Cryptococcus neoformans by human neutrophils. Evidence that fungal mannitol protects by scavenging reactive oxygen intermediates. J Immunol 1996;156:3836-40.

45. Wang Y, Aisen P, Casadevall A. Cryptococcus neoformans melanin and virulence: mechanism of action. Infect Immun 1995;63:3131-6.

46. Emery HS, Shelburne CP, Bowman JP, Fallon PG, Schulz CA, Jacobson ES. Genetic study of oxygen resistance and melanization in Cryptococcus neoformans. Infect Immun 1994:62:5694-7.

47. Schaffner A, Davis CE, Schaffner T, Markert M, Douglas H, Braude AI. In vitro susceptibility of fungi to killing by neutrophil granulocytes discriminates between primary pathogencity and opportunism. J Clin Invest 1986;78:511-24.

48. Frey CL, Drutz DJ. Influence of fungal surface components on the interaction of Coccidioides immitis with polymorphonuclear neutrophils. J Infect Dis 1986;153:933-43.

49. Drutz DJ, Huppert M. Coccidioidomycosis: factors affecting the host-parasite interaction. J Infect Dis 1983;147:372-90.

50. Brummer E, Beaman L, Stevens DA. Killing of endospores, but not arthroconidia, of Coccidioides immitis by immunologically activated polymorphonuclear neutrophils. In: Einstein HE, Catanzaro A, eds. Proceedings of 4th International Conference on Coccidioidomycosis. Washington: National Foundation for Infectious Disease, 1985:201-13.

51. Kozel TR, Pfrommer GST, Guerlain AS, Highison BA, Highison GJ. Strain variation in phagocytosis of Cryptococcus neoformans: dissociation of susceptibility to phagocytosis from activation and binding of opsonic fragments of C3. Infect Immun 1988;56:2794-800.

52. Eissenberg LG, Goldman WE, Schlesinger PH. Histoplasma capsulatum modulates the acidification of phagolysosomes. J Exp Med 1993;177:1605-11.

53. Beaman L, Benjamini E, Pappagianis D. Activation of macrophges by lymphokines: enhancement of phagosome-lysosome fusion and killing of Coccidioides immitis. Infect Immun 1983;39:1201-7.

54. Monga DP. Role of macrophages in resistance of mice to experimental cryptococcosis. Infect Immun 1981;32:975-8

55. Wu-Hsieh B, Zlotnik A, Howard DH. T-cell hybridoma-produced lymphokine that activates macrophages to suppress intracellular growth of Histoplasma capsulatum. Infect Immun 1984;43:380-5.

56. Mody CH, Lipscomb MF, Toews GB. Depletion of CD4+ (L3T4+) 
lymphocytes in vivo impairs murine host defence to Cryptococcus neoformans. J Immunol 1990;144:1472-7.

57. Beaman L. Fungicidal activation of murine macrophages by recombinant gamma interferon. Infect Immun 1987;55:2951-5.

58. Chen GH, Curtis JL, Mody $\mathrm{CH}$, Christensen PJ, Armstrong LR, Toews GB. Effect of granulocyte-macrophage colony-stimulating factor (GM-CSF) on rat alveolar macrophage anticryptococcal activity in vitro. J Immunol 1994;152:724-34.

59. Nassar F, Brummer E, Stevens DA. Effect of in vivo macrophage colony-stimulating factor on fungistasis of bronchoalveolar and peritoneal macrophages against Cryptococcus neoformans. Antimicrob Agents Chemother 1994;38:2162-4.

60. Cox RA, Kennell W. Suppression of T-Iymphocyte response by Coccidiodes immitis antigen. Infect Immun 1988;56:1424-9.

61. Murphy JW, Mosley RL. Regulation of cell mediated immunity in cryptococcosis. III. Characterization of second-order T suppressor cells (Ts2). J Immunol 1985;134:577-84.

62. Wheat LJ, Small CB. Disseminated histoplasmosis in the acquired immune deficiency syndrome. Arch Intern Med 1984;144:2147-9.

63. Chuck SL, Sande MA. Infections with Cryptococcus neoformans in the acquired immunodeficiency syndrome. N Engl J Med 1989;321:794-9.

64. Bronnimann DA, Adam RD, Galgiani JN, et al. Coccidiodomycosis in the acquired immunodeficiency syndrome. Ann Int Med 1987;106:372-9.

65. Galgiani JN, Ampel NM. Coccidioidomycosis in human immunodeficiency virus-infected patients. J Infect Dis 1990;162:1165-9.

66. Tewari RP, Sharma DK, Mathur A. Adoptive transfer of immunity from mice immunized with ribosomes or live cells of Histoplasma capsulatum. Infect Immun 1977;15:789-95.

67. Cozad GC, Chang C-K. Cell-mediated immunoprotection in blastomycosis. Infect Immun 1980;28:398-403.

68. Beaman L, Pappagianis D, Benjamini E. Mechanism of resistance to infection with Coccidioides immitis in mice. Infect Immun 1979;23:681-5

69. Huffnagle GB, Yates JL, Lipscomb MF. Immunity to a pulmonary Cryptococcus neoformans infection requires both $\mathrm{CD} 4+$ and CDS + T cells. J Exp Med 1991;173:793-800.

70. Deepe GSJ. Role of CD8 + T cells in host resistance to systemic infection with Histoplasma capsulatum in mice. J Immunol 1994;152:3491-500.

71. Williams DW, Weiner NW, Drutz DJ. Immunological studies of disseminated infection with Aspergillus fumigatus in the nude mouse. J Infect Dis 1981;143:726-33.

72. Denning DW, Follansbee SE, Scolaro M, Norris S, Edelstein H, Stevens DA. Pulmonary aspergillosis in the acquired immunodeficiency syndrome. N Engl J Med 1991;324:654-62.

73. Desai G, Nassar F, Brummer E, Stevens DA. Killing of Histoplasma capsulatum by macrophage colony stimulating factor-treated human monocyte-derived macrophages: role for reactive oxygen intermediates. J Med Microbiol 1995;43:224-9.

74. Harrison TS, Levitz SM. Mechanisms of impaired anticryptococcal activity in monocytes from donors infected with human immunodeficiency virus. J Infect Dis 1997;176:537-40.

75. Granger DL, Perfect JR, Durack DT. Macrophage-mediated fungistasis in vitro: requirements for intracellular and extracellular cytotoxicity. J Immunol 1986;136:672-80.

76. Lane TE, Wu-Hsieh BA, Howard DH. Antihistoplasma effect of activated mouse splenic macrophages involves production of reactive nitrogen intermediates. Infect Immun 1994;62:1940-5.

78. Michaliszyn E, Senechal S, Martel P, de Repentigny L. Lack of involvement of nitric oxide in killing of Aspergillus fumigatus conidia by pulmonary alveolar macrophages. Infect Immun 1995;63:2075-8.

79. Murphy JW, McDaniel DO. In vitro reactivity of natural killer (NK) cells against Cryptococcus neoformans. J Immunol 1982;128:1577-83.

80. Perkus AF, Baum LL. Natural killer cell inhibition of young spherules and endospores of Coccidioides immitis. J Immunol 1987;139:3107-11.

81. Zhang T, Kawakami K, Oureshi M, Okamura H, Kurimoto M, Saito A. Interleukin-12 (IL-12) and IL-18 synergistically induce the fungicidal activity of murine peritoneal exudate cells against cryptococcus neoformans through production of gamma interferon by natural killer cells. Infect Immun 1997;65:3594-9.

82. Murphy JW, Hidore MR, Wong SC. Direct interactions of human lymphocytes with the yeastlike organism, Cryptococcus neoformans. J Clin Invest 1993;91:1553-66.

83. Levitz SM, Dupont MP. Phenotypic and functional characterization of human lymphocytes activated by interleukin-2 to directly inhibit growth of Cryptococcus neoformans in vitro. J Clin Invest 1993;91:1490-8.

84. Levitz SM, North EA, Dupont MP, Harrison TS. Mechanisms of inhibition of Cryptococcus neoformans by human lymphocytes. Infect Immun 1995;63:3550-4.

85. Newman SL, Gootee L, Gabay JE. Human neutrophil-mediated fungistasis against Histoplasma capsulatum. Localization of fungistatic activity to the azurophil granules. J Clin Invest 1993;92:624-31.

86. Zhou P, Sieve MC, Bennett J, et al. IL-12 prevents mortality in mice infected with Histoplasma capsulatum through induction of IFN-gamma. J Immunol 1995;155:785-95.

87. Kawakami K, Qifeng X, Tohyarna M, Qureshi MH, Saito A. Contribution of tumour necrosis factor-alpha (TNF-alpha) in host defence mechanism against Cryptococcus neoformans. Clin Exp Immunol 1996;106:468-74.

88. Kawakami K, Kohno S, Kadota J, et al. T cell-dependent activation of macrophages and enhancement of their phagocytic activity in the lungs of mice inoculated with heat-killed Cryptococcus neoformans: involvement of IFN-gamma and its protective effect against cryptococcal infection. Microbiol Immunol 1995;39:135-43.

89. Huffnagle GB, Toews GB, Burdick MD, et al. Afferent phase production of TNF-alpha is required for development of protective T cell immunity to Cryptococcus neoformans. J Immunol 1996;157:4529-36.

90. Cross CE, Collins HL, Bancroft GJ. CR3-dependent phagocytosis by murine macrophages: different cytokines regulate ingestion of a defined CR3 ligand and complement-opsonized Cryptococcus neoformans. Immunology 1997;91:289-96.

91. Liles WC, Huang JE, van Burik JA, Bowden RA, Dale DC. Granulocyte colony-stimulating factor administered in vivo augments neutrophil-mediated activity against opportunistic fungal pathogens. J Infect Dis 1997;175:1012-5

92. Roilides E, Uhlig K, Venzon D, Pizzo PA, Walsh TJ. Enhancement of oxidative response and damage caused by human neutrophils to Aspergillus fumigatus hyphae by granulocyte colony stimulating factor and gamma interferon. Infect Immun 1993;61:1185-93.

93. Lovchik JA, Lyons CR, Lipscomb MF. A role for gamma interferon-induced nitric oxide in pulmonary clearance of Cryptococcus neoformans. Am J Respir Cell Mol Biol 1995; 13:116-24.

94. Magee DM, Cox RA. Roles of gamma interferon and interleukin-4 in genetically determined resistance to Coccidioides immitis. Infect Immun 1995;63: 3514-9.

95. Magee DM, Cox RA. Interleukin-12 regulation of host defences against Coccidioides immitis. Infect Immun 1996;64:3609-13.

96. Nicholson WJ, Slight J, Donaldson K. Inhibition of the transcription factors NF-kappa B and AP-I underlies loss of cytokine gene expression in rat alveolar macrophages treated with a diffusible product from the spores of Aspergillus fumigatus. Am J Respir Cell Mol Biol 1996;15:88-96.

97. Vecchiarelli A, Retiai C, Monari C, Taseini C, Bistoni F, Kozel TR. Purified capsular polysaccharide of Cryptococcus neoformans induces interleukin-10 secretion by human monocytes. Infect Immun 1996;64:2846-9.

98. Levitz SM, North EA. Lymphoproliferation and cytokine profiles in human peripheral blood mononuclear cells stimulated by Cryptococcus neoformans. J Med Vet Mycol 1997;35:229-36.

99. Corry DB, Ampel NM, Christian L, Locksley RM, Galgiani JN. Cytokine production by peripheral blood mononuclear cells in human coccidioidomycosis. J Infect Dis 1996;174:440-3.

100. Paya MK. Fungal infections in solid organ transplantation. Clin Infect Dis 1992;16:677-88.

101. Katzung BG. Basic and Clinical Pharmacology, sixth edn. Norfolk: Appleton and Lange, 1995:823-79.

102. Hoffman JM, Potasman I, Baldwin JC, Oyer PE, Stinson EB, Remington JS. Infectious complications in heart transplant 
recipients receiving cyclosporine and prednisone.

Ann Intern Med 1987;106:209-16.

103. Dummer JS, Hardy A, Poorsattar A, Ho M. Early infections in kidney, heart, and liver transplant recipients on cyclosporine. Transplantation 1983;36:259-67.

104. Morrison VA. The infectious complications of chronic lymphocytic leukemia. Semin Oncol 1998;25:98-106.

105. Devi SJ. Preclinical efficacy of a glucuronoxylomannan-tetanus toxoid conjugate vaccine of Cryptococcus neoformans in a murine model. Vaccine 1996;14:841-4.

106. Murray HW. Current and future clinical applications of interferon-gamma in host antimicrobial defence. Intensive Care Med 1996;22(Suppl 4):S456-61.

107. Gately MK, Mulqueen MJ. Interleukin-12: potential clinical applications in the treatment and prevention of infectious diseases. Drugs 1996;52(Suppl 2):18-26. 


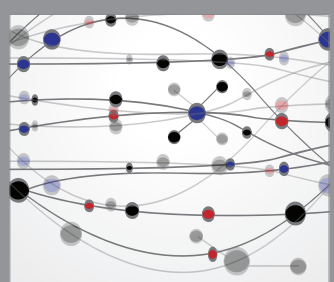

The Scientific World Journal
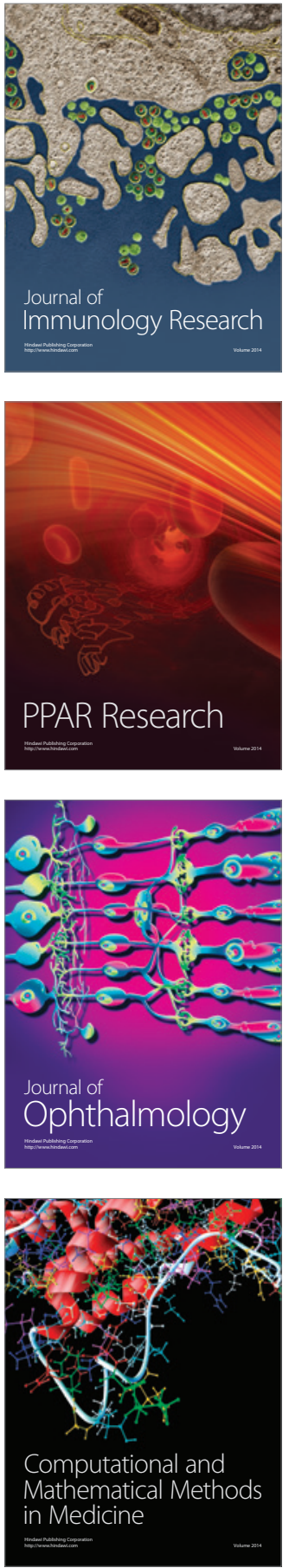

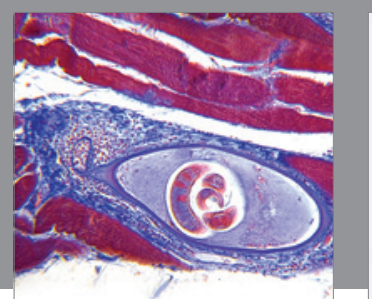

Gastroenterology Research and Practice

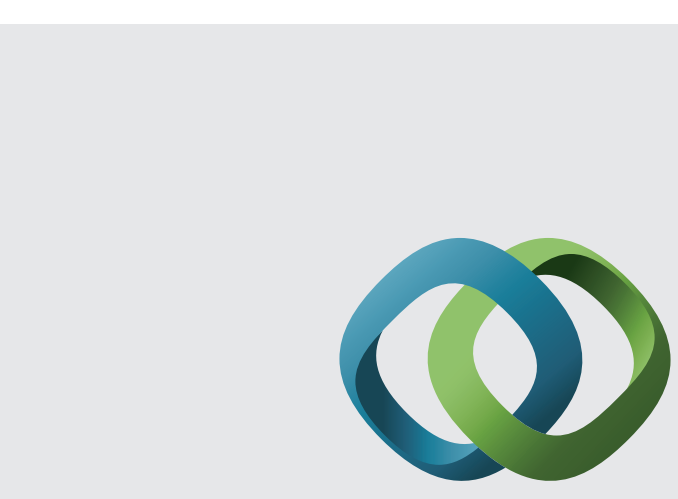

\section{Hindawi}

Submit your manuscripts at

http://www.hindawi.com
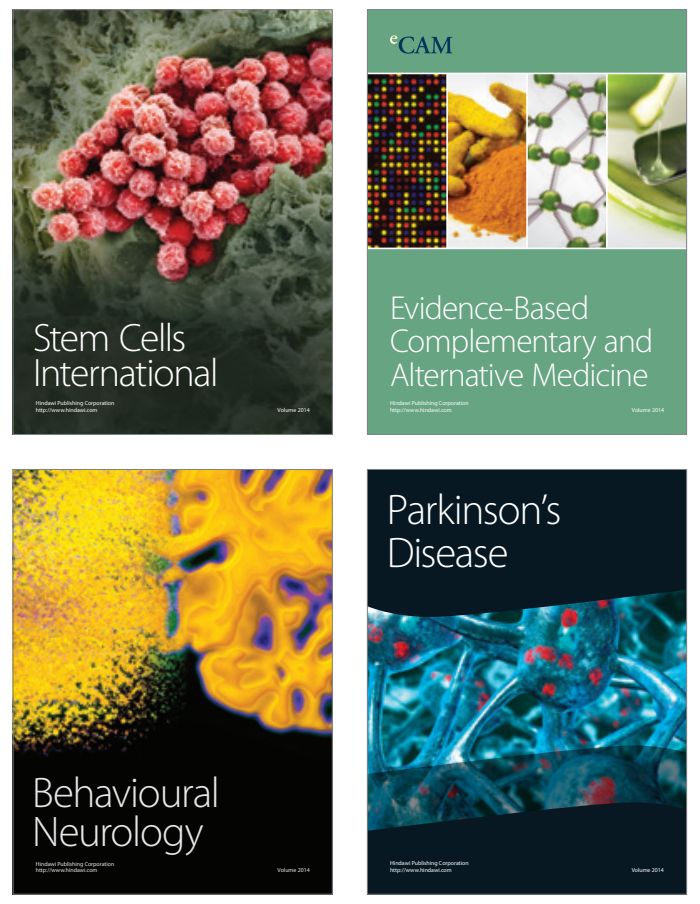
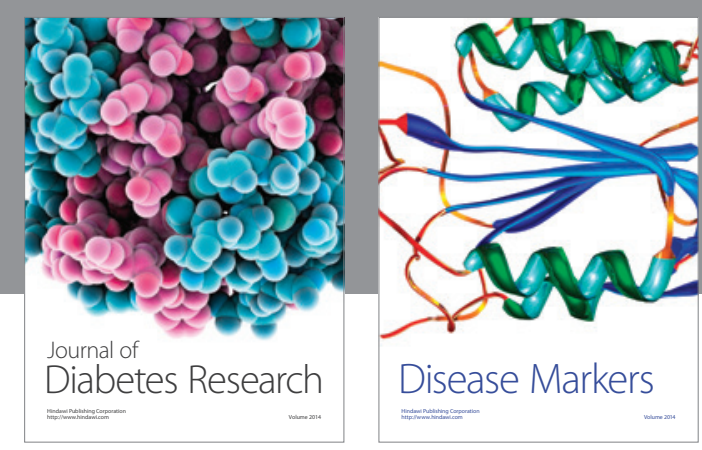

Disease Markers
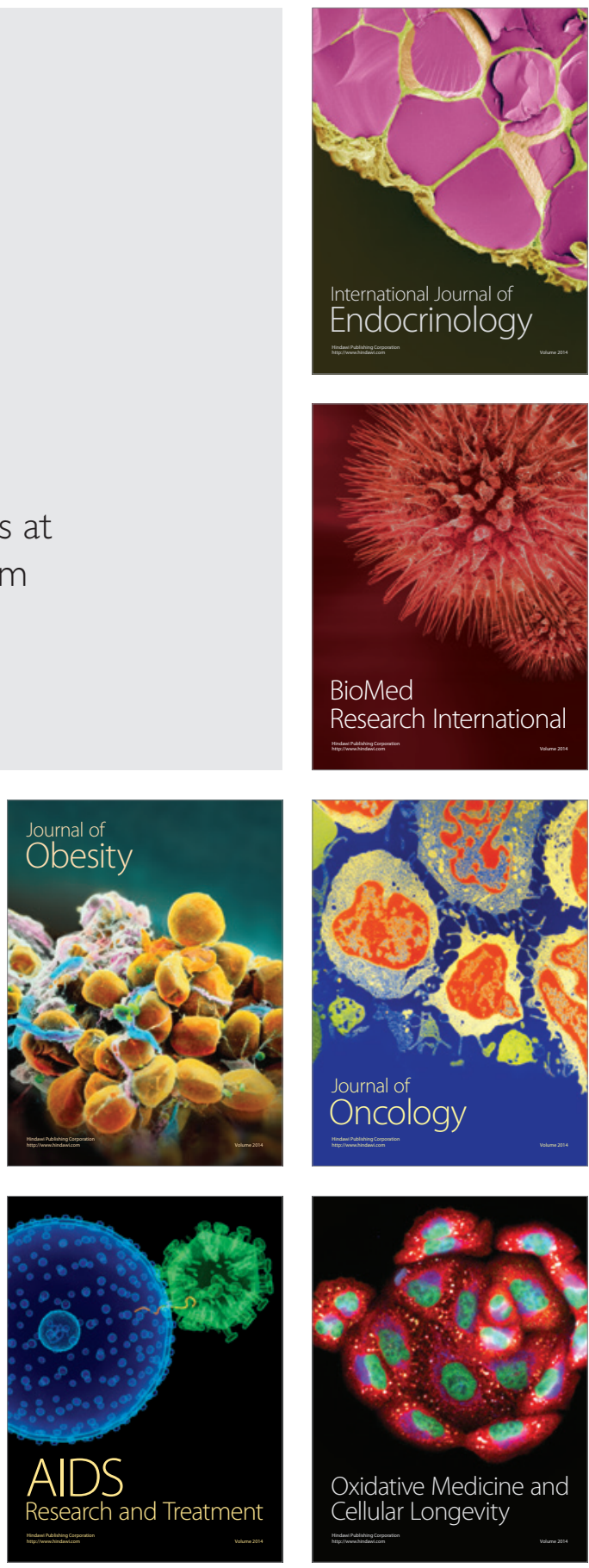